\title{
Priming is swell, but it's far from simple
}

\section{Citation}

Ziegler, J., J. Snedeker, \& E. Wittenberg. 2017. Priming is swell, but it's far from simple Icommentary on Branigan \& Pickering's "An experimental approach to linguistic representation"). Behavioral and Brain Sciences 40: 44-45.

\section{Permanent link}

http://nrs.harvard.edu/urn-3:HUL.InstRepos:39666439

\section{Terms of Use}

This article was downloaded from Harvard University's DASH repository, and is made available under the terms and conditions applicable to Open Access Policy Articles, as set forth at http:// nrs.harvard.edu/urn-3:HUL.InstRepos:dash.current.terms-of-use\#OAP

\section{Share Your Story}

The Harvard community has made this article openly available.

Please share how this access benefits you. Submit a story.

\section{Accessibility}


This is the authors' copy of the final unpublished version of this manuscript. The Version of Record is available at:

https://doi.org/10.1017/S0140525X17000607

Please cite as:

Ziegler, J., Snedeker, J., \& Wittenberg, E. (2017). Priming is swell, but it's far from simple (commentary on Branigan \& Pickering's "An experimental approach to linguistic representation"). Behavioral and Brain Sciences, 40, 44-45.

\title{
Priming is swell, but it's far from simple
}

\author{
Jayden Ziegler, Jesse Snedeker, and Eva Wittenberg
}

\begin{abstract}
Clearly, structural priming is a valuable tool for probing linguistic representation. But we don't think that the existing results provide strong support for B\&P's model, largely because the priming effects are more confusing and diverse than their theory would suggest. Fortunately, there are a number of other experimental tools available, and linguists are increasingly making use of them.
\end{abstract}

\section{MAIN TEXT}

Branigan \& Pickering (B\&P) tell a straightforward tale. Linguists rely on grammaticality judgments to uncover representations. Judgments have limitations, but no (other) psycholinguistic methods systematically reveal linguistic structure. Fortunately, priming offers a direct window onto representation, providing evidence for two distinct levels: a surface syntactic form, independent of meaning and void of lexical content, and a semantic form that includes information about thematic roles, quantifier scope, and information structure.

We are fond of priming ourselves, but this elegant story is misleading in several ways.

First, the priming literature does not strongly support the theory that B\&P propose. As they dive deeper, the loose ends and contradictions emerge, but their final conclusions bypass this complexity. If we rearrange the evidence a bit, the theoretical ambiguity becomes clearer.

The primary evidence for syntactic representations comes from studies of argument alternations (dative or active-passive) that perfectly confound surface syntax with thematic mappings. B\&P note that a few foundational studies demonstrated that syntax can be primed independent of thematic mappings (section 2.1). Thus, they privilege syntax in their theory. But there is now an equally robust literature demonstrating that thematic mappings can be primed independent of 
syntax (e.g., Cai et al., 2012; Chang et al., 2003; Cho-Reyes et al., 2016; Hare \& Goldberg, 1999; Salamoura \& Williams, 2007; Ziegler \& Snedeker, 2016a). B\&P acknowledge this work (2.4), but treat it as a secondary, interface phenomenon: thematic information remains separate from syntax (Figure 1).

Similarly, the observation that priming can occur in the absence of lexical overlap motivates a theory in which the syntactic skeleton is separate from the lexical content. To account for the lexical boost, B\&P must complicate their story, by linking lemmas to structures (2.3). But perhaps we should revisit the claim that the syntactic structure lacks lexical nodes. Indeed, function words can be a locus of priming (Bencini et al., 2002; Ferreira, 2003). We know that only partial overlap in the syntactic skeleton is needed for structural priming (2.1), but we don't assume that the unnecessary pieces are removed from the syntactic representation. Lexical content may be similar: always present and sometimes contributing to priming via overlap.

The evidence for their semantic level is also sparse. We know: quantifier scope can be primed, this priming is isolated to the particular quantifier used (e.g., each does not prime every), and it abstracts away from the nouns and verbs in a sentence (Feiman \& Snedeker, 2016; Raffray \& Pickering, 2010). However, B\&P's claim that scopal priming is bound to thematic roles and cannot be captured by an LF representation is controversial (Chemla \& Bott, 2015). It rests on a single null result with prime stimuli ("A boy climbed every tree") that have not been shown to produce priming when thematic roles are the same. Furthermore, the manipulation used confounds verb-specific roles, thematic roles, and the notion of deep subject/object. It's just too early to conclude that scope and thematic roles are tightly coupled, or that LF isn't the locus of scopal priming.

It seems that under the right conditions almost any linguistic representation, mapping, or process can be primed. Consequently, evidence for priming is always interpretable to some degree (it demonstrates a commonality between prime and target). But the absence (or magnitude) of an effect is often less constraining, because there is so much variability across tasks and stimuli. In some comprehension tasks, there is no priming in the absence of verb overlap (Arai et al., 2007), while in others, abstract priming is robust (Thothathiri \& Snedeker, $2008 \mathrm{a} / \mathrm{b}$ ). This problem isn't unique to comprehension. The pattern of effects in production can depend on how the sentences are elicited (stem completion vs. full sentence generation; Ziegler \& Snedeker, 2016b).

Understanding this instability is critical; we suspect that the answer lies in thinking through the processes involved in each task and how they engage both stored representations and representations that are constructed on the fly. To do this, we will have to move beyond the notion of priming as a static, atemporal phenomenon that targets stable representations independent of the process of production (or comprehension).

While priming is not the transparent window that B\&P promise, psycholinguists do have a much wider range of tools than the paper suggests. Some are behavioral. Novel word generalization studies going back to the 1950 s have revealed structural regularities in the representation of 
linguistic form and meaning (Berko, 1958; Fisher, 2002; Gropen et al., 1989; Naigles, 1990; Prasada \& Pinker, 1993). Similarly, artificial language learning sheds light on the representations learners extract from linguistic data and use to guide generalization (Pothos, 2007; Reber, 1967; Saffran et al., 2008; for review, see Erickson \& Thiessen, 2015).

New methods for analyzing imaging data also provide greater constraint on representational theories. For example, multi-voxel pattern analysis, a class of machine learning algorithms that examine patterns of neural activity (Haxby et al., 2001), has revealed regions of the left temporal cortex that appear to bind arguments to something roughly like thematic roles (Frankland \& Greene, 2015).

Structural priming is therefore only one useful tool of many.

Finally, we think that B\&P are too pessimistic in their assessment of linguists and their tools. There are long-standing traditions of experimental work in phonetics, phonology, and language acquisition. In recent years, experimental work has also become common in syntax, semantics, and pragmatics (e.g., Arunachalam, 2013; Cowart, 1997; Myers, 2009; Sorace \& Keller, 2005). Indeed, the question of how armchair judgments translate into generalizable conclusions has received considerable attention (Sprouse \& Almeida, 2012; Sprouse et al., 2013). From our perspective, the remaining disputes do not reflect an over-reliance on grammaticality judgments or a dearth of appropriate methodologies; they stem from: the close parallels between the theories that are still standing (similar operations assigned to different theoretical levels), the lack of falsifiability for the contrasting features, and the danger we all face of letting our "affection for [our] intellectual child[ren]" (Chamberlin, 1897) guide our interpretation of the data. 


\section{REFERENCES}

Arai, M., van Gompel, R. P. G., \& Scheepers, C. (2007). Priming ditransitive structures in comprehension. Cognitive Psychology, 54, 218-250.

Arunachalam, S. (2013). Experimental methods for linguists. Language and Linguistics Compass, 7(4), 221-232.

Bencini, G., Bock, K., \& Goldberg, A. (2002). How abstract is grammar? Evidence from structural priming in language production. Poster presented at the 15th Annual Meeting of the CUNY Conference on Human Sentence Processing, New York, NY.

Berko, J. (1958). The child's learning of English morphology. WORD, 14(2-3), 150-177.

Cai, Z. G., Pickering, M. J., \& Branigan, H. P. (2012). Mapping concepts to syntax: Evidence from structural priming in Mandarin Chinese. Journal of Memory and Language, 66(4), 833-849.

Chamberlin, T. C. (1897). Studies for students: The method of multiple working hypotheses. The Journal of Geology, 5(8), 837-848.

Chang, F., Bock, K., \& Goldberg, A. E. (2003). Can thematic roles leave traces of their places? Cognition, 90, 29-49.

Chemla, E., \& Bott, L. (2015). Using structural priming to study scopal representations and operations. Linguistic Inquiry, 46(1), 157-172.

Cho-Reyes, S., Mack, J. E., \& Thompson, C. K. (2016). Grammatical encoding and learning in agrammatic aphasia: Evidence from structural priming. Journal of Memory and Language, 91, 202-218.

Cowart, W. (1997). Experimental syntax: Applying objective methods to sentence judgments. Thousand Oaks: Sage.

Erickson, L. C., \& Thiessen, E. D. (2015). Statistical learning in language: Theory, validity, and predictions of a statistical learning account of language acquisition. Developmental Review, 37, 66-108.

Feiman, R., \& Snedeker, J. (2016). The logic in language: How all quantifiers are alike, but each quantifier is different. Cognitive Psychology, 87, 29-52.

Ferreira, V. S. (2003). The persistence of optional complementizer production: Why saying "that" is not saying "that" at all. Journal of Memory and Language, 48, 379-398.

Fisher, C. (2002). Structural limits on verb mapping: The role of abstract structure in 2.5-yearolds' interpretation of novel verbs. Developmental Science, 5(1), 55-64.

Frankland, S. M., \& Greene, J. D. (2015). An architecture for encoding sentence meaning in left mid-superior temporal cortex. Proceedings of the National Academy of Sciences of the United States of America, 112(37), 11732-11737. doi:10.1073/pnas.1421236112

Gropen, J., Pinker, S., Hollander, M., \& Goldberg, R., \& Wilson, R. (1989). The learnability and acquisition of the dative alternation in English. Language, 65(2), 203-257.

Hare, M. L., \& Goldberg, A. E. (1999). Structural priming: Purely syntactic? In M. Hahn \& S. C. Stones (Eds.), Proceedings of the 21st Annual Meeting of the Cognitive Science Society (pp. 208-211). Mahwah, NJ: Erlbaum.

Haxby, J. V., Gobbini, M. I., Furey, M. L., Ishai, A., Schouten, J. L., \& Pietrini, P. (2001). Distributed and overlapping representations of faces and objects in ventral temporal cortex. Science, 293, 2425-2429. 
Myers, J. (2009). The design and analysis of small-scale syntactic judgment experiments. Lingua, 119, 425-444. doi:10.1016/j.lingua.2008.09.003

Naigles, L. (1990). Children use syntax to learn verb meanings. Journal of Child Language, 17(2), 357-374.

Pothos, E. M. (2007). Theories of artificial grammar learning. Psychological Bulletin, 133(2), 227-244.

Prasada, S., \& Pinker, S. (1993). Generalization of regular and irregular morphological patterns. Language and Cognitive Processes, 8, 1-56.

Raffray, C. N., \& Pickering, M. J. (2010). How do people construct logical form during language comprehension? Psychological Science, 21(8): 1090-1097.

Reber, A. S. (1967). Implicit learning of artificial grammars. Journal of Verbal Learning and Verbal Behavior, 6(6), 855-863.

Saffran, J. R., Hauser, M. D., Seibel, R., Kapfhamer, J., Tsao, F., \& Cushman, F. (2008). Grammatical pattern learning by human infants and cotton-top tamarin monkeys. Cognition, 107, 479-500.

Salamoura, A, \& Williams, J. N. (2007). Processing verb argument structure across languages: Evidence for shared representations in the bilingual lexicon. Applied Psycholinguistics, 28, 627-660.

Sorace, A., \& Keller, F. (2005). Gradience in linguistic data. Lingua, 115, 1497-1524.

Sprouse, J., \& Almeida, D. (2012). Assessing the reliability of textbook data in syntax: Adger's Core Syntax. Journal of Linguistics, 48, 609-652.

Sprouse, J., Schütze, C. T., \& Almeida, D. (2013). A comparison of informal and formal acceptability judgments using a random sample from Linguistic Inquiry 2001-2010. Lingua, 134, 219-248.

Thothathiri, M., \& Snedeker, J. (2008a). Give and take: Syntactic priming during spoken language comprehension. Cognition, 108(1), 51-68.

Thothathiri, M., \& Snedeker, J. (2008b). Syntactic priming during language comprehension in three- and four-year-old children. Journal of Memory and Language, 58, 188-213.

Ziegler, J., \& Snedeker, J. (2016a). Toward a comprehensive view of structural priming: What gets primed when. Poster presented at the 29th Annual Meeting of the CUNY Conference on Human Sentence Processing, Gainesville, FL.

Ziegler, J., \& Snedeker, J. (2016b). Structural priming across development: The lexical boost, abstract priming, and task demands. Poster presented at the 41st Boston University Conference on Language Development, Boston, MA. 